\title{
Cavitation Bubbles Remove and Inactivate Listeria and Salmonella on the Surface of Fresh Roma Tomatoes and Cantaloupes
}

\author{
Joshua J. Lee ${ }^{1}$, Joseph D. Eifert ${ }^{1 *}$, Sunghwan Jung ${ }^{2}$ and Laura K. Strawn ${ }^{3}$ \\ ${ }^{1}$ Department of Food Science and Technology, Virginia Tech, Blacksburg, VA, United States, ${ }^{2}$ Department of Biomedical \\ Engineering and Mechanics, Virginia Tech, Blacksburg, VA, United States, ${ }^{3}$ Eastern Shore Agricultural Research and \\ Extension Center, Virginia Tech, Painter, VA, United States
}

\section{OPEN ACCESS}

Edited by:

Joshua B. Gurtler,

Agricultural Research Service (USDA),

United States

Reviewed by:

Agnes Kilonzo-Nthenge, Tennessee State University,

United States

Dike Ukuku,

Beltsville Agricultural Research Center, Agricultural Research Service (USDA),

United States

Ömer Akineden,

Justus Liebig Universität Gießen,

Germany

${ }^{*}$ Correspondence: Joseph D. Eifert jeifert@vt.edu

Specialty section: This article was submitted to Agro-Food Safety,

a section of the journa

Frontiers in Sustainable Food Systems

Received: 12 June 2018

Accepted: 28 August 2018

Published: 19 September 2018

Citation:

Lee JJ, Eifert JD, Jung S and Strawn LK (2018) Cavitation Bubbles

Remove and Inactivate Listeria and Salmonella on the Surface of Fresh Roma Tomatoes and Cantaloupes. Front. Sustain. Food Syst. 2:61. doi: 10.3389/fsufs.2018.00061
Raw produce has frequently been identified as the source of bacterial pathogens that can cause human illnesses, including listeriosis and salmonellosis. Microbial pathogens may attach and form biofilms on raw fruit surfaces and can be difficult to remove. A cavitation process (injection of bubbles into water) was studied for its effectiveness for removal and inactivation of Listeria monocytogenes and Salmonella Newport from the surfaces of fresh Roma tomatoes and cantaloupes. Individual fruit were separately inoculated with each pathogen, then submerged in a water tank and treated with a bubble flow through an air stone using one airflow rate (0-14 liters/min.) for up to $60 \mathrm{~s}$. As airflow increased, L. monocytogenes reduction on tomato and cantaloupe surfaces increased up to 1.2 and $0.8 \log$ CFU/fruit greater than with water alone (no bubbles), respectively. With a 14 L/min flow rate, Salmonella reduction on tomato and cantaloupe surfaces increased up to 0.9 and $0.7 \log$ CFU/fruit greater than when no bubbles applied, respectively. Also, with the bubble treatments, additional pathogen reduction (detached organisms) was observed in the tank water. Therefore, these bubble streams can be used to enhance the detachment of bacteria from fruit surfaces and to inactivate a proportion of these detached microorganisms. Additionally, recoveries of Salmonella from inoculated Roma tomatoes and cantaloupe were determined for treatment water that contained 50 or 150 ppm sodium hypochlorite. Combining both cavitating bubbles and 150 ppm chlorine in the tank water resulted in greater efficacy of removing or inactivating $S$. Newport from the surface of cantaloupe (2.9 log CFU) than with cavitation (2.5 log CFU) or chlorine (1.9 log $\mathrm{CFU}$ ) alone. The physical force of a bubble stream on raw produce can effectively detach and inactivate surface bacteria, and has the potential to reduce antimicrobial chemical use and water use in post-harvest packing operations.

\section{Keywords: cavitation, bubbles, fruit, Listeria, Salmonella}

\section{INTRODUCTION}

Listeria monocytogenes and Salmonella bacteria account for over 1 million reported cases of foodborne illnesses every year. Furthermore, listeriosis and salmonellosis may lead to more than 24,000 hospitalizations and nearly 700 deaths each year (Scallan et al., 2011). Moreover, these illness cases result in high medical costs, including 365 million dollars a year for Salmonella alone 
(Center for Diseases Control and Prevention, 2010). Foodborne illness caused by L. monocytogenes and Salmonella could be reduced through additional efforts to prevent these organisms from adhering to or surviving on raw food surfaces. Physical or chemical procedures to remove surface bacteria are variably effective and can damage surface textures leading to loss of quality and structural integrity.

Fruits and vegetables are often consumed raw, which increases the risk of ingesting foodborne pathogens (Burnett and Beuchat, 2000; Food and Drug Administration, 2003). Listeria and Salmonella contamination can take place at any step of food production and processing, including planting, growing, and harvesting (Beuchat, 2002). Tomatoes can be contaminated by pathogens through a variety of ways (Asplund and Nurmi, 1991). In the past few decades, tomatoes have frequently been associated with contamination by Salmonella, often resulting in multi-state outbreaks, and numerous illnesses. Salmonella Newport has been recognized in a number of illness outbreaks, particularly with tomato crops (Greene et al., 2008). Tomatoes are a major agricultural crop in America, with over 500,000 acres utilized solely for tomatoes, consisting of a 2-billion-dollar industry (USDA, 2010). In a comprehensive study from 1990 to 2010, researchers found that illness outbreaks associated with raw tomatoes resulted in 1,959 illnesses in the United States, with 384 hospitalizations, and 3 deaths. Roma tomatoes were the second most common produce item associated with $23 \%$ of the illness outbreaks (Bennett et al., 2015). As an example, a restaurant chain in Minnesota was found to have been the source of an outbreak of Salmonella Newport contaminated tomatoes, resulting in 115 reported cases of salmonellosis (Eikmeier, 2016).

Another produce item, cantaloupe, have been problematic in regards to food safety. In the past decade, cantaloupes have been linked to multiple illness outbreaks and recalled product (Center for Disease Control and Prevention, 2012). Cantaloupes are consumed raw, and their uniquely irregular surface may enhance biofilm formation and foodborne pathogen survival. Cantaloupes (Cucumis melo var. reticulus) are the second leading melon for consumption in the United States (Boriss, 2014). They are characterized by a rough netted surface. The deep grooves and pockets of the cantaloupe surface are visibly clear to the naked eye, and especially through topographical modeling (Wang et al., 2009). Moreover, the cantaloupe produces a natural, waxy substance on its surface, making it more hydrophobic, and thus more difficult for water and sanitizer to effectively clean the surface (Bastos et al., 2005).

Cantaloupes are often placed through a washing system, to remove visible debris, followed by a chemical sanitation wash, most often with chlorine or hydrogen peroxide (Ukuku and Fett, 2002). Despite these treatments, pathogen contamination on the outer surfaces of cantaloupes can occur. Large illness outbreaks due to cantaloupe have occurred in the past decade. In 2011, Jensen Farms was the origin of a 28-state L. monocytogenes outbreak beginning in Colorado, resulting in 147 cases, 143 hospitalizations, and 33 deaths (Center for Disease Control and Prevention, 2012). The following year, another outbreak took place in Kentucky, this time concerning Salmonella, where 261 cases were reported, as well as three deaths (Lopez et al., 2016).
Tomatoes also undergo a washing process once delivered from the field. Most often, tomatoes pass through a flume system, which washes away large amounts of debris, such as soil or rocks, followed by treatment with a commercial sanitizer. Most commercial sanitizers utilize a chemical cleaning agent, such as chlorine or organic acids. The process may or may not include brushes or rollers for more efficacious cleaning (Wang and Ryser, 2014).

Within the past three decades, cavitation as a treatment methodology for the removal of bacteria has become more common, but more so in the fields of dentistry and orthodontics. Cavitation refers to the formation of vapor cavities (e.g., bubbles) in a liquid due to forces acting upon the liquid. Cavitation usually occurs when a liquid is subjected to rapid changes in pressure that cause the formation of cavities. Cavitation processes include ultrasound and sonication methods to destroy microbial populations on teeth (Marotti et al., 2013). The effects of cavitation have been studied for many years including instances where the collapse of rapidly-moving bubbles in water led to the disintegration of rocks in waterfalls, and metal propellers in ships and submarines (Rayleigh, 1917; Birkhoff, 1957).

The destructive action of collapsing cavitation bubbles is due to the shock waves emitted after the first rebound of a collapsing bubble and due to microjets formed by bubbles collapsing near a solid wall (van Wijngaarden, 2016). The collapse of these cavitation bubbles near a rigid boundary results in high-speed reentrant liquid jets, which penetrate the bubbles and strike the nearby boundary generating water hammer like impact pressures. Additionally, the shear and lift forces generated can be effective for removing dirt particles (or bacteria) from a surface to be cleaned (Chahine et al., 2016).

Cavitation occurs in two forms: non-inertial and inertial (also known as stable cavitation). The first forms cavitating bubbles through an input of high energy, such as highpressure differentials, as shown by the destroyed metal boat propellers. Another example is ultrasound treatment, employed in dentistry applications, as well as in the food industry. Inertial cavitation does not require a pressure differential or other high-energy inputs, and relies on bubble production through injected air (Feng, 2011). Inertial cavitation can still produce impressive amounts of force, and high-intensity inertial cavitation is currently used in the food industry to generate emulsions, disrupt cells, promote chemical reactions, inhibit enzymes, tenderize meat and modify crystallization processes (McClements, 1995).

Lower intensity inertial cavitation is currently used as a pasteurization technique in many drink industries, such as juice and diary. In the dairy industry, microbial populations are inactivated by bubble generation (Chandrapala et al., 2012). In addition, cavitation is applied in industries to deactivate enzymes in apple and carrot juice (O’Donnell et al., 2010). This paper reports the efficacy of low intensity cavitation, through injected air, as a treatment method to reduce and inactivate surface bacteria pathogens on fresh roma tomatoes and cantaloupe. Additionally, the proportion of pathogen transfer from inoculated to uninoculated roma tomatoes was evaluated after exposure to a bubble stream. Finally, pathogenic organism 
recovery from each fruit and the treatment water was compared for fruit immersed in water with and without chlorine.

\section{MATERIALS AND METHODS}

We compared cavitation treatments for their efficacy in removing or inactivating Listeria monocytogenes and Salmonella Newport from the surface of fresh cantaloupe and Roma tomatoes. An airflow passingd through a porous air stone generated bubbles in tank water. Fruits, inoculated with bacteria were submerged in the tank water for 30 or $60 \mathrm{~s}$, and then these microorganisms were enumerated from the fruit and tank water. Additionally, we examined the degree of cross-contamination that can occur between contaminated and uncontaminated fruit due to a cavitation treatment. Thirdly, we compared cavitation treatments with and without the presence of sodium hypochlorite solutions. Applications of chlorine solutions are the most common method for reducing the microbial load on fresh produce today (Waters and Hung, 2014).

\section{PATHOGEN CULTIVATION AND INOCULATION}

\section{Listeria monocytogenes}

Four strains of the pathogen Listeria monocytogenes (including serotypes $1 / 2 \mathrm{a}, 1 / 2 \mathrm{~b}$, and $4 \mathrm{~b}$ ) were combined into a cocktail in equivalent proportions. These serotypes are most frequently implicated in foodborne illness (Food and Drug Administration, 2015). Specifically, L. monocytogenes (strains Scott A, 4b-J1815, R2-503, and LM 0042) were obtained from the culture collection of the Department of Food Science and Technology, Virginia Polytechnic Institute and State University. Each strain was separately cultivated in trypticase soy broth (TSB) (BBL, BD Diagnostics, Sparks, MD, U.S.A.) supplemented with $0.6 \%$ yeast extract (Acros Organics, Fair Lawn, NJ) for $36 \pm 2 \mathrm{~h}$ at $36 \pm 2^{\circ} \mathrm{C}$. Once each strain was subcultured, each was plated onto Oxford agar to confirm morphology and concentration.

\section{Salmonella Newport}

A $S$. Newport culture with resistance to $50 \mathrm{ppm}$ Nalidixic acid was obtained from the culture collection of the Department of Food Science and Technology, Virginia Polytechnic Institute and State University. Nalidixic acid resistance was used to select for inoculated organisms in the presence of naturally occurring organisms. Cultures were maintained on Tryptic Soy Agar (TSA) (Difco - Becton Dickinson, Fisher Scientific, Pittsburgh, PA) plates or Tryptic Soy Broth (TSB) supplemented with $50 \mathrm{ppm}$ Nalidixic acid. The concentration of cells, as well as culture purity were confirmed through the TSA plating.

\section{Fruit Inoculation}

Ripe Roma tomatoes were purchased from local grocery markets and stored at $4^{\circ} \mathrm{C}$. Each Roma tomato was placed onto a sterile holding plate, and $100 \mu \mathrm{l}$ of the L. monocytogenes cocktail culture $\left(\sim 10^{9} \mathrm{CFU} / \mathrm{ml}\right)$ was spot inoculated onto each tomato individually. Each tomato was dried inside a biosafety cabinet for $1 \mathrm{~h}$. The same procedure was used for $S$. Newport inoculation, with $100 \mu l$ spot inoculations placed on separate Roma tomatoes. Cultures were serially diluted onto Oxford agar plates or Tryptic Soy Agar (TSA) supplemented with $50 \mathrm{ppm}$ Nalidixic acid for enumeration of L. monocytogenes or Salmonella Newport, respectively.

Ripe cantaloupes (Cucumis melo var. reticulus) were purchased from a local grocery market, and stored in their original box without modified atmosphere at $4^{\circ} \mathrm{C}$. Inoculation of the cantaloupes was similar to that of the tomatoes; however with a higher inoculum quantity. Five $100 \mu \mathrm{l}$ spots were placed on the surface of the cantaloupe, for a total of $500 \mu \mathrm{l}$ of $L$. monocytogenes or $S$. Newport cocktail per cantaloupe. The cantaloupes remained on sterile holding plates to air-dry in a biosafety cabinet for $1 \mathrm{~h}$.

\section{CAVITATION TREATMENT}

Cavitation bubbles were generated using a motorized air pump with adjustable airflow outputs (Active Aqua (Hydrofarm) model AAPA70L). The motorized air pump was connected to an air stone (Uxcell \#B5014), which was placed at the bottom of a water chamber. The air stone was held at the bottom of the water chamber by water-proof tape. Tomatoes were treated in smaller chambers (TopFin 1 gallon $(3.8 \mathrm{~L})$ plastic aquarium), while cantaloupes were treated in larger chambers (TopFin 2.6 gallon $(9.8 \mathrm{~L})$ glass aquarium). The distance between the fruit and the air stones was approximately $6-8 \mathrm{~cm}$.

\section{Roma Tomatoes}

After the 1-h drying period, each inoculated Roma tomato was placed individually into the smaller water chamber with $2,000 \mathrm{~mL}$ distilled water. The lid of each water chamber had a small camera tripod drilled into it to assure that the Roma tomato remained directly above the stream of bubbles, while also allowing it to naturally turn and move within the bubbles. Bubbles were generated using one of five different airflows: 0 (control), 3.5, 7, 10.5, or 14 Standard Liters Per Minute (SLPM). The airflow rate was measured by an airflow meter (Omega FMA-LP1600A). Treatment times were either 30 or 60 . Iindividual Roma tomatoes were inoculated and treated separately for one combination of airflow (5) and treatment time (2), and pathogen (2). These experiments were repeated in triplicate for a total of 60 fruit analyzed.

\section{Cantaloupe}

Cavitation treatment for cantaloupes followed the same general procedure as for tomatoes. After the 1-h drying period, each inoculated cantaloupe was placed individually into the larger water chamber with $5,000 \mathrm{~mL}$ distilled water. Bubbles were generated using one of five different airflows: 0 (control), 3.5, 7, 10.5, and 14 Standard Liters Per Minute (SLPM) and airflow rate was measured by an airflow meter (Omega FMA-LP1600A). Treatment times were either 30 or 60 . Individual cantaloupe were inoculated and treated separately for one combination of airflow (5) and treatment time (2), and pathogen (2). These experiments were repeated in triplicate for a total of 60 fruit analyzed. 


\section{QUANTITATIVE RECOVERY OF PATHOGENS FROM FRUIT}

After the 30 or 60 s cavitation treatment, each fruit was aseptically placed into a sterile stomacher bag with buffered peptone water (99 $\mathrm{mL}$ per Roma tomato, $500 \mathrm{~mL}$ for cantaloupe) and shaken by hand for $2 \mathrm{~min}$ (Food and Drug Administration, 2016). For L. monocytogenes recovery, this solution was serially diluted onto Oxford agar plates. For Salmonella Newport recovery, the solution from each stomacher bag was serially diluted and spread plated onto Tryptic Soy Agar (TSA) supplemented with $50 \mathrm{ppm}$ Nalidixic acid. Plates were incubated at $36 \pm 2{ }^{\circ} \mathrm{C}$ for $36 \pm 2 \mathrm{~h}$. After incubation, plates were counted using an automated colony counter (ProtoCol; Microbiology International, Frederick, MD).

\section{RECOVERY AND QUANTIFICATION OF BACTERIA FROM TANK WATER}

After inoculated fruit were removed from the treatment tanks, $100 \mu \mathrm{l}$ of the remaining water in the chamber was removed from the tank and directly plated onto the appropriate selective agars (Oxford agar for L. monocytogenes and TSA with $50 \mathrm{ppm}$ Nalidixic acid for $S$. Newport recovery). Additional ten-fold dilutions of the tank water were plated and then incubated at 36 $\pm 2^{\circ} \mathrm{C}$ for $36 \pm 2 \mathrm{~h}$ and enumerated as described previously.

\section{CROSS-CONTAMINATION FROM INOCULATED TO UNINOCULATED ROMA TOMATOES}

The proportion of pathogen transfer from inoculated to uninoculated roma tomatoes was evaluated after exposure to a bubble stream. One Roma tomato was inoculated with $100 \mu \mathrm{l}$ of L. monocytogenes culture and placed into the $3.8 \mathrm{~L}$ chamber with 2,000 mL distilled water and one uninoculated Roma tomato. The two tomatoes in the tank were treated for either 30 or $60 \mathrm{~s}$ with one of three airflow rates of 0 (control), 7 or 14 SLPM. These experiments were repeated in triplicate for a total of 36 fruit analyzed (half were uninoculated). After each treatment, the tomatoes were removed and placed into individual stomacher bags with $99 \mathrm{~mL}$ of buffered peptone water. L. monocytogenes were recovered from each tomato as previously described in the quantitative recovery step. Bacteria remaining in the tank water were enumerated following the procedure outlined in the water quantification step. These tests with inoculated and uninoculated tomatoes were conducted, in triplicate, with $S$. Newport for a total of 36 fruit analyzed (half were uninoculated).

\section{CHLORINE SOLUTION TREATMENT OF ROMA TOMATOES AND CANTALOUPE}

\section{Chlorine Only}

The proportion of viable $S$. Newport recovered from each fruit and the treatment water was used to compare fruit treated with and without chlorine. Individual Roma tomatoes were inoculated with $100 \mu \mathrm{l}$ of the $S$. Newport culture as described above, and placed into $2,000 \mathrm{ml}$ distilled water. The water inside the chamber was supplemented with sodium hypochlorite $(\mathrm{NaOCl})$ at a concentration of either 0 (control), 50 or 150 ppm (Ritenour et al., 2002). After 30 or $60 \mathrm{~s}$, the Roma tomatoes were removed and quantified for $S$. Newport as outlined above. Also, the remaining water in the treatment tank was also enumerated for $S$. Newport as described earlier. Three trials were repeated for each combination of time and chlorine concentration for a total of 18 fruit analyzed. Additionally, these tests were conducted in triplicate with cantaloupes inoculated with $S$. Newport (500 ul) and submerged in 5,000 mL distilled water. Salmonella population levels were determined for each fruit and the tank water were compared for fruit treated with and without chlorine in the tank water. For both fruits, a neutralizing agent (BD Difco D/E neutralizing broth) was used to determine if residual chlorine on the fruits or in the tank water reduced pathogen recovery. Use of the neutralizing agent did not present any difference in pathogen recovery when compared to pathogen recovery numbers without the neutralizing agent (data not shown).

\section{Chlorine and Cavitation}

Individual Roma tomatoes were inoculated with $100 \mu$ l of the $S$. Newport culture, and placed into $2,000 \mathrm{ml}$ distilled water. Sodium hypochlorite concentrations in the water were either 0 (control), 50 or $150 \mathrm{ppm}$. Each Roma tomato was treated for either 30 or $60 \mathrm{~s}$. For each combination of chlorine concentration and treatment time, bubbles were applied using an airflow rate of 14 SLPM. Three trials were conducted for each combination of chlorine concentration, cavitation, and treatment time for a total of 18 fruit analyzed. After treatment, the Roma tomatoes were removed and quantified for $S$. Newport as outlined above. The remaining water in the treatment tank was also enumerated for $S$. Newport as outlined above. Additionally, these tests were repeated in triplicate with cantaloupes inoculated with $S$. Newport $(500 \mu \mathrm{l})$ and submerged in $5000 \mathrm{~mL}$ distilled water. The proportion of viable Salmonella recovered from each fruit and the tank water were compared for fruit treated with and without cavitation for chlorinated water $(0,50$, or $150 \mathrm{ppm} \mathrm{NaOCl})$.

\section{DATA ANALYSIS}

Organism counts enumerated from produce surfaces and the organism counts recovered from tank water were compared to the original inoculum level to determine the proportion of viable organisms that were attached to the fruit after treatment, the proportion removed in the water, and the proportion that could not be recovered. The analysis of the recovery of pathogens on the surface of produce items and in the water include the differences between specific flow rates, times, pathogens, and mean of recovered organisms. A one-way analysis of variance (ANOVA) were used to determine significant differences between means for each variable tested at a statistical significance of $\alpha=0.05$. Where the ANOVA indicated a difference between means, Tukey's multiple range test was used to assess significant differences between means. All calculations were performed with $\mathrm{R}^{\circledR}$ 3.2.5 Statistical Software (R Core Team, 2016). 


\section{RESULTS AND DISCUSSION}

\section{Recovery of Pathogens From the Surface of Fruits and Tank Water}

Cavitation treatment of Roma tomatoes and cantaloupe led to a pathogen reduction of $0.6-1.3 \mathrm{log} /$ fruit greater than that measured when no bubbles were applied (Table 1). This level of removal or inactivation was similar to that of other researchers (Scouten and Beuchat, 2002; Seymour et al., 2002). The increases in $\log$ reduction were statistically significant $(P<0.05)$ for most of the airflow rates. As the airflow rate increased, the recovery of pathogens followed the general trend of decreasing for both fruits and both pathogens. At each airflow rate, the difference in $\log$ recovery between 30 and 60 s of treatment was not statistically significant $(P>0.05)$.

TABLE 1 | Log reductions of inoculated pathogens on Roma tomatoes and cantaloupe for all airflow rates and exposure times.

\begin{tabular}{|c|c|c|c|c|c|c|}
\hline & \multirow{2}{*}{$\begin{array}{c}\text { Time } \\
\text { (s) }\end{array}$} & \multirow[b]{2}{*}{0} & \multicolumn{3}{|c|}{ Airflow rate (SLPM) } & \multirow[b]{2}{*}{14} \\
\hline & & & 3.5 & 7 & 10.5 & \\
\hline \multicolumn{7}{|l|}{ TOMATOES } \\
\hline \multirow[t]{2}{*}{ L. monocytogenes } & 30 & $1.56^{\mathrm{a}}$ & $1.69^{b}$ & $1.92^{\mathrm{C}}$ & $2.23^{d}$ & $2.57^{\mathrm{e}}$ \\
\hline & 60 & $1.71^{\mathrm{A}}$ & $1.82^{\mathrm{B}}$ & $2.05^{\mathrm{C}}$ & $2.34^{d}$ & $2.89^{e}$ \\
\hline \multirow[t]{2}{*}{ Salmonella Newport } & 30 & $1.34^{\mathrm{a}}$ & $1.63^{b}$ & $1.76^{\mathrm{C}}$ & $1.88^{\mathrm{C}}$ & $2.06^{d}$ \\
\hline & 60 & $1.31^{\mathrm{a}}$ & $1.54^{\mathrm{B}}$ & $1.73^{\mathrm{C}}$ & $1.92^{d}$ & $2.23^{\mathrm{E}}$ \\
\hline \multicolumn{7}{|l|}{ CANTALOUPES } \\
\hline \multirow[t]{2}{*}{ L. monocytogenes } & 30 & $1.90^{\mathrm{a}}$ & $2.07^{b}$ & $2.28^{C}$ & $2.39 \mathrm{c}$ & $2.55^{\mathrm{d}}$ \\
\hline & 60 & $1.86^{\mathrm{a}}$ & $2.02^{b}$ & $2.19^{\mathrm{C}}$ & $2.31^{d}$ & $2.63^{\mathrm{E}}$ \\
\hline \multirow[t]{2}{*}{ Salmonella Newport } & 30 & $2.10^{\mathrm{a}}$ & $2.30^{b}$ & $2.43^{C}$ & $2.46^{\mathrm{C}}$ & $2.65^{d}$ \\
\hline & 60 & $2.23^{\mathrm{A}}$ & $2.30^{\mathrm{a}}$ & $2.48^{b}$ & $2.65^{\mathrm{C}}$ & $2.88^{\mathrm{D}}$ \\
\hline
\end{tabular}

$a, b, c, d, e$ Denotes significant differences $(P<0.05)$ from previous airflow rates. $A, B, C, D, E$ Denotes significant differences $(P<0.05)$ in time.
Figure 1 shows the log recovery of both L. monocytogenes and $S$. Newport as a function of airflow rate. As the airflow rate increases, surface pathogen recovery decreased for both pathogens. At the highest airflow rate, pathogen population recovery decreased by a mean level of $1.1 \log \mathrm{CFU} /$ tomato and $0.7 \log \mathrm{CFU} / \mathrm{cantaloupe}$. Airflow rate was statistically significant $(P<0.05)$ in the removal or inactivation of pathogen populations on both tomatoes and cantaloupe. After recovery of the pathogens on the surface of Roma tomatoes and cantaloupes, the water remaining in the treatment chamber was enumerated at all five different levels of airflow rates to determine any effect of cavitation on pathogens in the water.

Figure 2 shows the log recovery of both L. monocytogenes and $S$. Newport as a function of airflow rate in the treatment water. Pathogen recovery generally decreased with higher airflow rates. At the highest airflow rate, pathogen population recovery from the water decreased by a mean level of $0.4 \log \mathrm{CFU} /$ tomato and $0.2 \log \mathrm{CFU} /$ cantaloupe. Airflow rate was statistically significant $(P<0.05)$ in the inactivation of pathogen populations in the treatment water. Application of cavitation bubbles led to a decrease in the pathogens on the fruit and a decrease in pathogen populations in the tank water.

Figure 3 shows the log recovery of L. monocytogenes from Roma tomatoes and tank water as a function of treatment time. At each airflow rate, the difference in log recovery between 30 and $60 \mathrm{~s}$ of treatment was not statistically significant $(P>0.05)$ for the removal of pathogen populations. Also, the recovery of $S$. Newport from Roma tomato surfaces was not significantly different when bubbles were applied for 30 vs. $60 \mathrm{~s}$ (data not shown). Figure 4 shows the log recovery of $S$. Newport from cantaloupe and tank water as a function of treatment time (30 or $60 \mathrm{~s})$. At each airflow rate, the difference in recovery between 30 and $60 \mathrm{~s}$ of treatment are not statistically significant $(P>0.05)$ in the removal of pathogen populations. Also, the recovery of L. monocytogenes from cantaloupe surfaces was not significantly

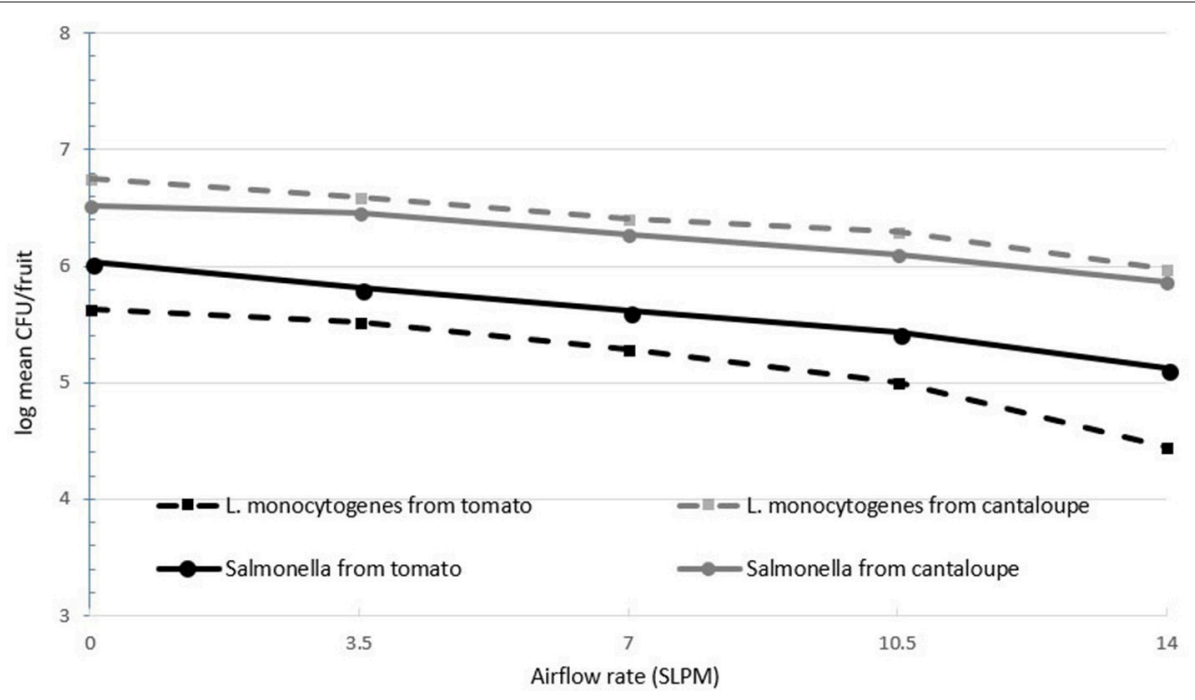

FIGURE 1 | Recovery of inoculated L. monocytogenes and Salmonella Newport from the surfaces of Roma tomatoes and cantaloupe ( $n=6)$. 


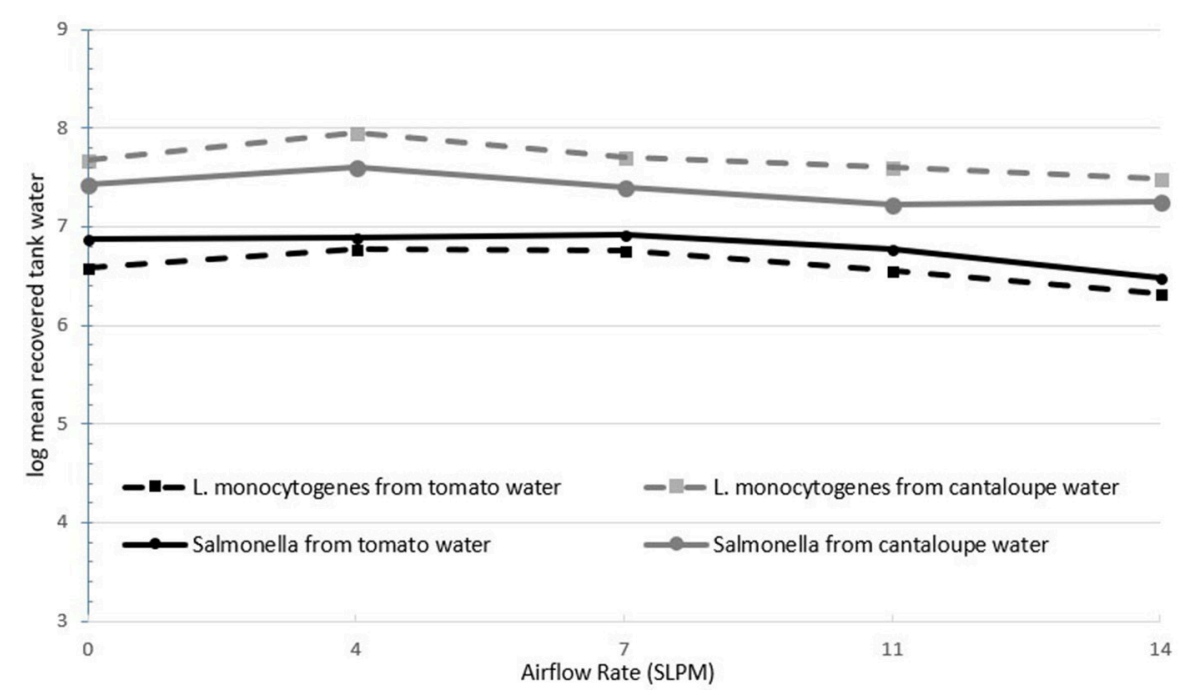

FIGURE 2 | Recovery of inoculated L. monocytogenes and Salmonella Newport from tank water post-treatment for each fruit ( $n=6)$.

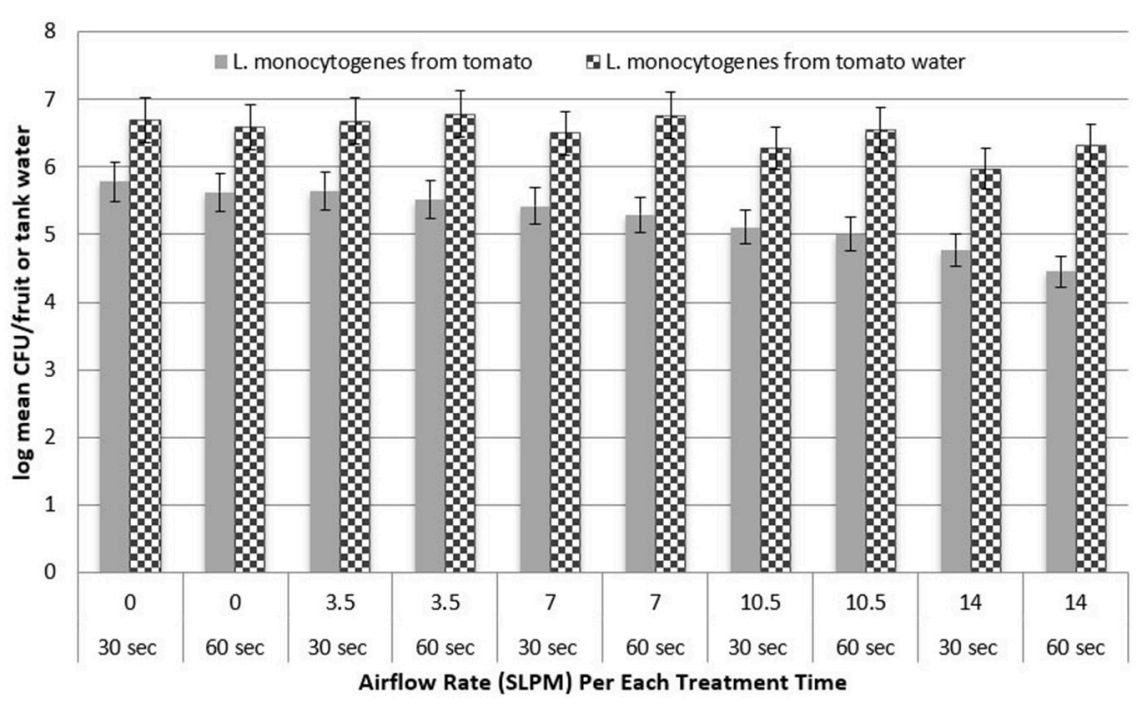

FIGURE 3 | Recovery of inoculated $L$. monocytogenes from the surface of Roma tomatoes and recovered from the water post-treatment $(n=3)$.

different when bubbles were applied for 30 vs. $60 \mathrm{~s}$ (data not shown).

In the tank water post-treatment, an increase in pathogen recovery was observed consistently when airflow rate increased from 0 to 3.5 SPLM in airflow rate. This suggests that removal of pathogens from the surface of the fruit remains in the water at viable levels. However, as the airflow rate increases, the pathogen population significantly decreases. This suggests further that higher airflow rates have the ability to inactivate both $S$. Newport as well as L. monocytogenes. Moreover, the higher the airflow rate, the more effective the inactivation. The results of the enumeration of treatment water coincide with the observations that L. monocytogenes adhere better to cantaloupes. The recovery of $L$. monocytogenes post-treatment of inoculated cantaloupe was less than that of $S$. Newport. Similar to fruit surface enumeration, a significant difference in recovery was not observed between the two treatment times. In preliminary experiments with $S$. Newport, treatment times up to $5 \mathrm{~min}$, compared to $60 \mathrm{~s}$, did not significantly reduce pathogen recovery in the tank water at similar airflow rates. However, the efficacy of cavitation for inactivating bacteria (reduced recovery) in the tank water was significantly different between fruit types and between pathogens. L. monocytogenes had significantly less inactivation than $S$. Newport. This may suggest greater resistance of $L$. monocytogenes to the effects of cavitation. 


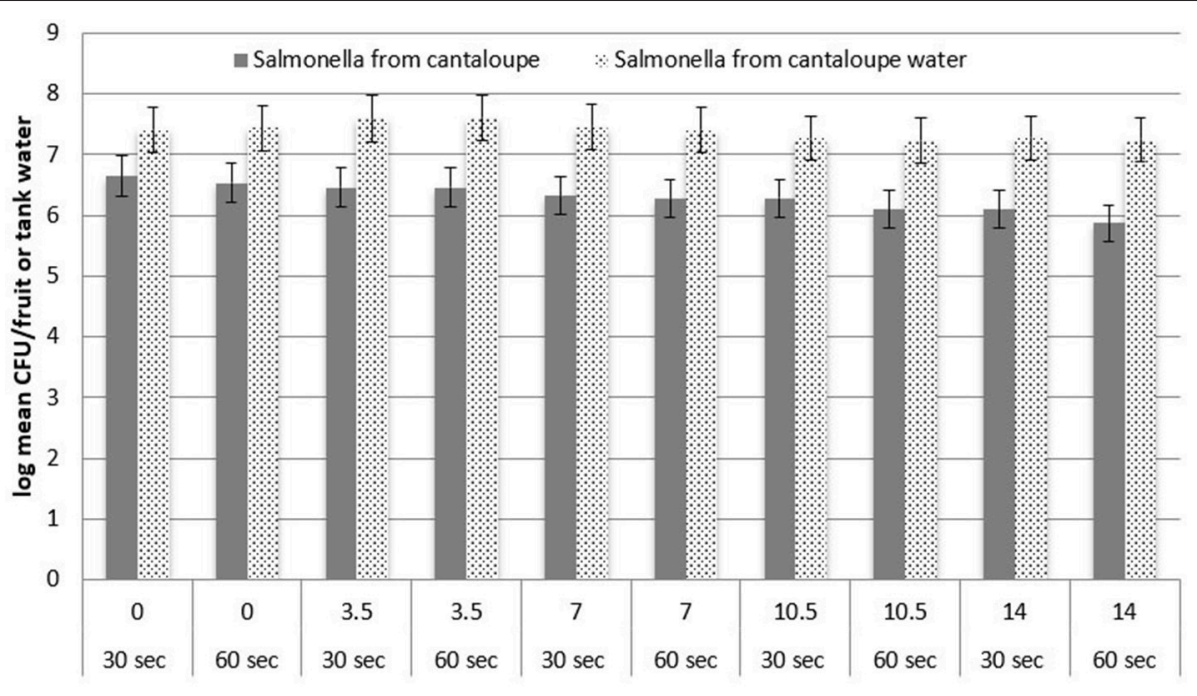

Airflow Rate (SLPM) Per Each Treatment Time

FIGURE 4 | Recovery of inoculated Salmonella from the surface of cantaloupes and recovered from the water post-treatment, as a function of treatment time $(n=3)$.

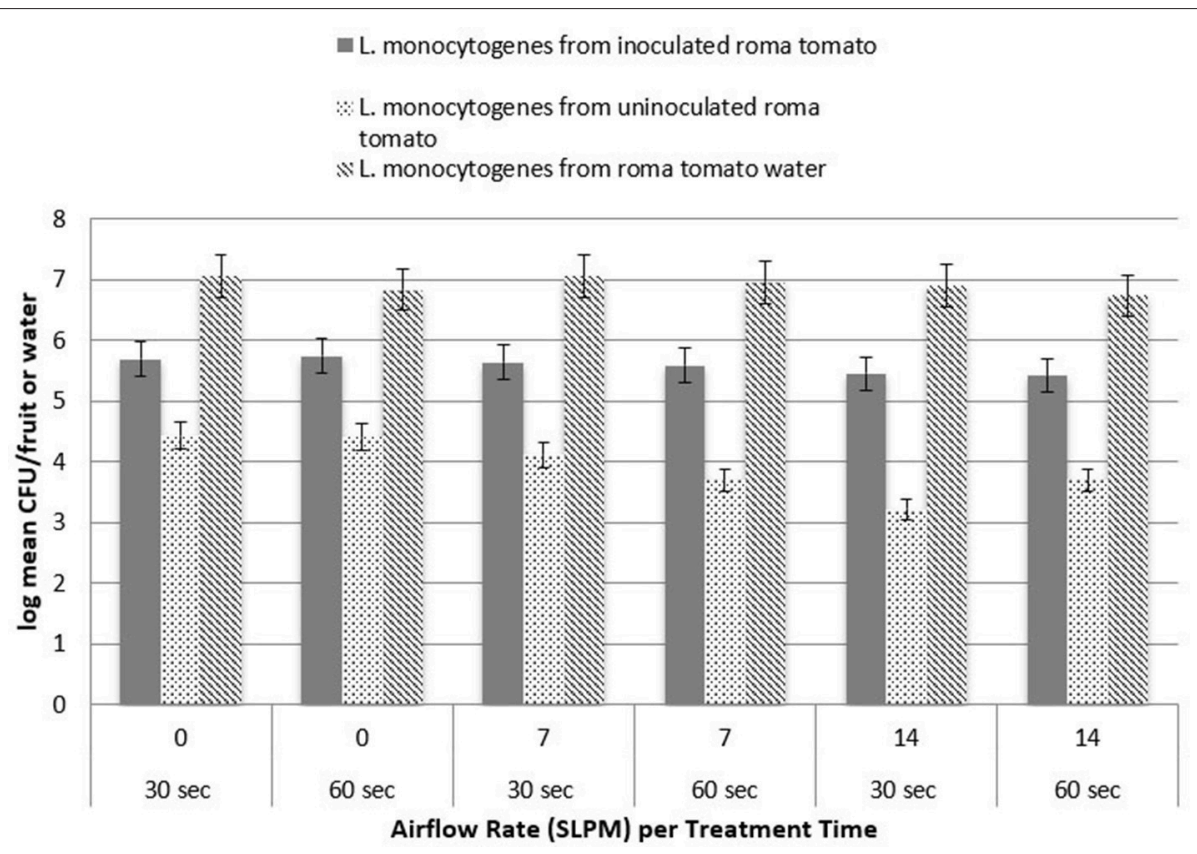

FIGURE 5 | Recovery of $L$. monocytogenes from inoculated and uninoculated Roma tomatoes, as a function of treatment time ( $n=3)$.

\section{Cross Contamination From Inoculated Roma Tomatoes}

The potential for pathogen cross contamination was studied by treating an inoculated Roma tomato simultaneously with an uninoculated Roma tomato. Three levels of airflow were utilized to determine the level of cross contamination from inoculated to uninoculated Roma tomatoes during simultaneous cavitation treatment. Figure 5 shows the log recovery from the uninoculated Roma tomatoes for $L$. monocytogenes as a function of the three airflow rates. Approximately 4.3 $\log \mathrm{CFU} /$ tomato was recovered from uninoculated tomatoes submerged in water with no bubbles. After cavitating bubbles were applied, recovery was reduced by $\sim 0.5 \log$ CFU/tomato. While the inoculated tomato and pathogen recovery in the treatment water showed no significant difference between treatment times $(P>0.05)$, there was a significant difference in treatment times $(P<0.05)$ in the transfer of pathogens to the uninoculated tomato. Transfer and recovery of $S$. Newport 
followed a similar trend where pathogen recovery decreased with a higher airflow (Figure 6). Airflow rate was statistically significant $(P<0.05)$ in the removal or inactivation of pathogen populations. However, higher airflow rates resulted in less total adherence of pathogens onto the uninoculated Roma tomato. In other words, after pathogens transferred from the inoculated Roma tomato to the uninoculated Roma tomato, cavitation at the higher airflow rates removed or inactivated pathogens on the surface of the uninoculated tomato.

Treatment times, either 30 or $60 \mathrm{~s}$, were statistically significant $(P<0.05)$ with fewer organisms remaining on the uninoculated Roma tomato after the longer treatment time. This suggests that cross contamination occurs within $30 \mathrm{~s}$. The pathogen may detach from the inoculated Roma tomato and adhere to the uninoculated Roma tomato, and then may be removed or inactivated a second time during the ongoing cavitation treatment.

\section{Efficacy of Combined Chlorine and Cavitation Treatment}

At each of the three chlorine concentrations of 0,50 , and $150 \mathrm{ppm}$, two different levels of airflow rates were utilized to determine the efficacy of cavitation compared with a chlorine wash, as well as to observe any increased efficacy in combining chlorine and cavitation. Figure 7 shows the log reduction of $S$. Newport for Roma tomatoes as a function of both airflow rates and chlorine concentration. The reduction of $S$. Newport populations on the surface of Roma tomatoes was significantly higher $(P<0.05)$ with $150 \mathrm{ppm}$ of chlorine, compared to $50 \mathrm{ppm}$ chlorine. Moreover, at the higher airflow rate, log reduction of $S$. Newport from the surface of Roma tomatoes was significantly

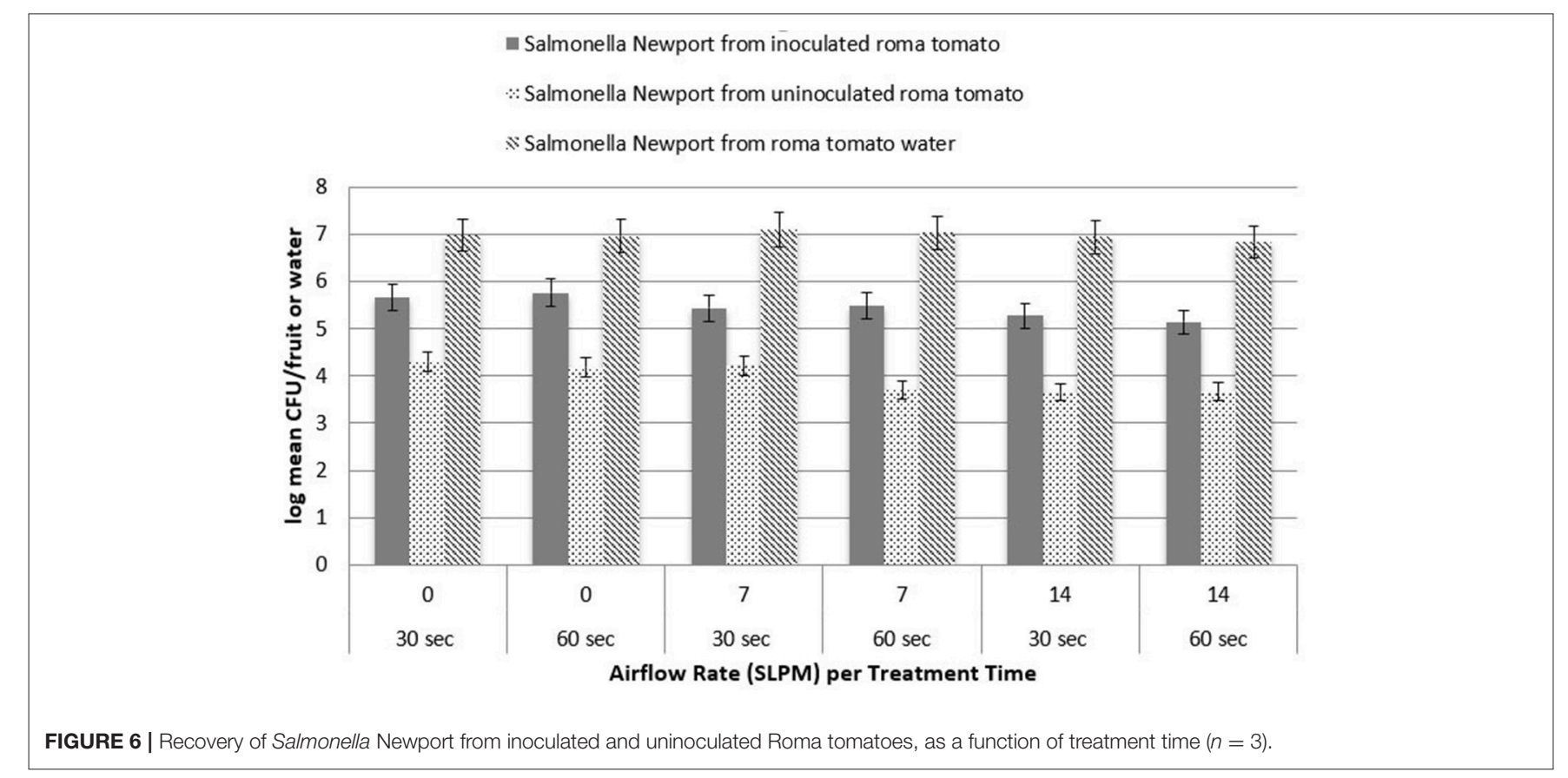

E 6 Recovery of Salmonella Newport from inoculated and uninoculated Roma tomatoes, as a function of treatment time $(n=3)$

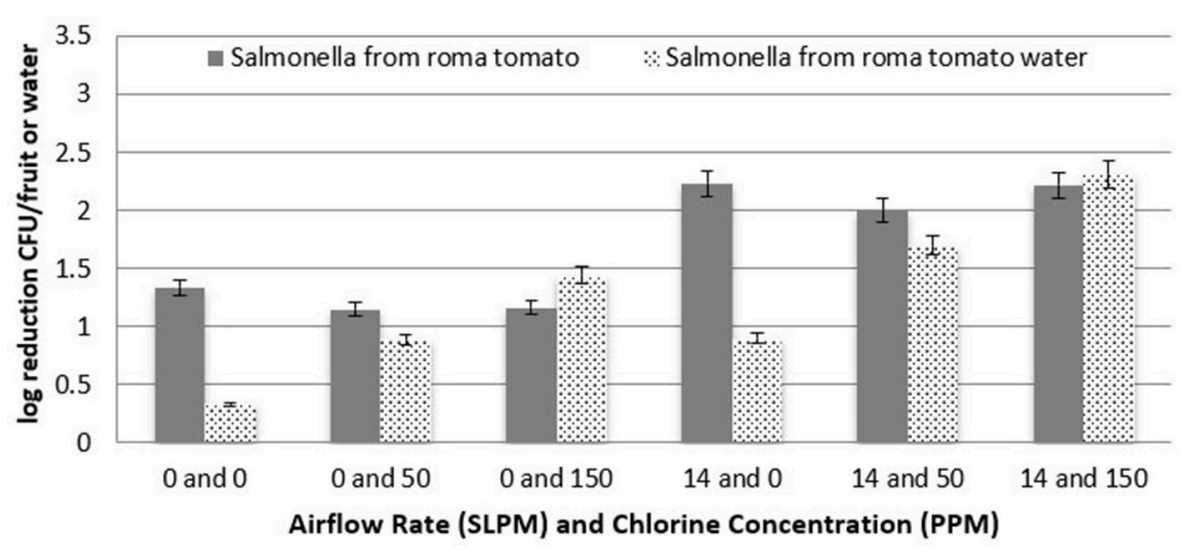

FIGURE 7 | Log reduction of Salmonella on Roma tomatoes as a function of airflow rate and chlorine concentration ( $n=6)$. 


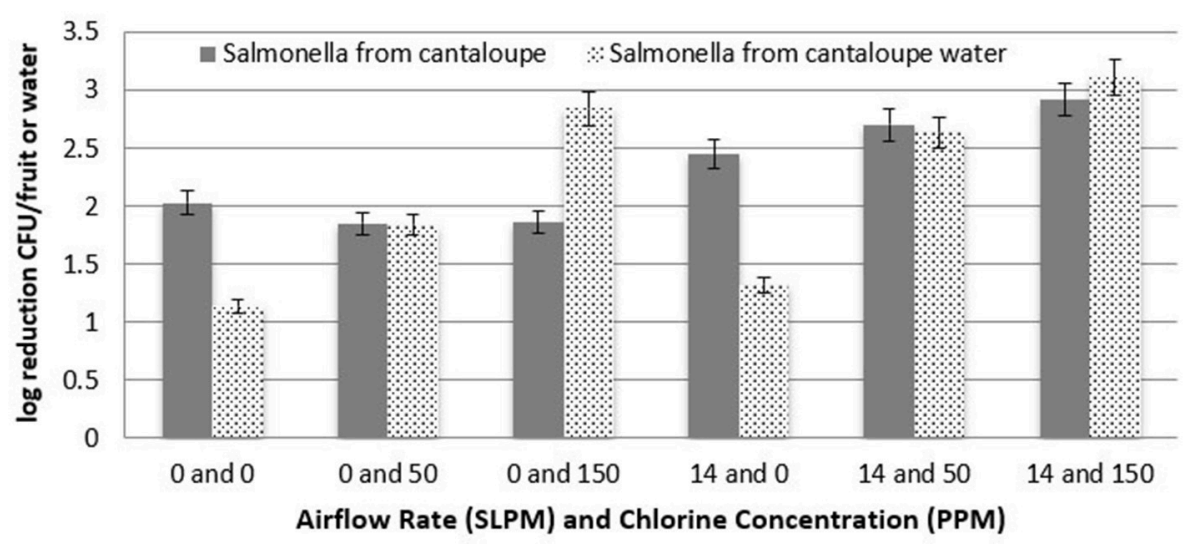

FIGURE 8 | Log reduction of Salmonella on cantaloupes as a function of airflow rate and chlorine concentration $(n=6)$.

higher $(P<0.05)$ compared to no airflow rate. Combining both cavitating bubbles and $150 \mathrm{ppm}$ chlorine in the tank water resulted in a similar efficacy (log reduction of $2.2 \log$ CFU/fruit) of removing or inactivating $S$. Newport from the surface of roma tomatoes compared with cavitation alone. Mean log reductions using chlorine and no bubbles was only $1.2 \log$ CFU per tomato.

Similar to the Roma tomatoes, log recovery of $S$. Newport from the surface of cantaloupes followed the same trend of significantly higher reduction $(P<0.05)$ with a $150 \mathrm{ppm}$ chlorine concentration vs. $50 \mathrm{ppm}$, as seen in Figure 8. Furthermore, the higher airflow rate was significantly more effective $(P<$ $0.05)$ at reducing $S$. Newport populations than when no bubbles were injected. Combining both cavitating bubbles and $150 \mathrm{ppm}$ chlorine in the tank water resulted in greater efficacy of removing or inactivating $S$. Newport from the surface of cantaloupe (2.9 $\log \mathrm{CFU})$ than with cavitation $(2.5 \log \mathrm{CFU})$ or chlorine (1.9 $\log$ $\mathrm{CFU})$ alone.

After fruit were removed from the treatment tanks, the tank water was enumerated to determine the level of Salmonella that detached and survived. Figure 7 shows the log reduction of $S$. Newport in the treatment tank water for Roma tomatoes as a function of both airflow rates and all three chlorine concentrations. There is a clear trend of higher reduction (lower recovery) as chlorine concentration increases, for both airflow rates. Each increment of increased chlorine concentration was significantly higher in $\log$ reduction $(P<0.05)$. Similarly, the bubble applications at $14 \mathrm{~L} / \mathrm{min}$ led to a significantly lower recovery $(P<0.05)$ than when no bubbles were applied.

Figure 8 shows the enumeration of treatment tank water at each combination of airflow rate and chlorine concentration for cantaloupes. As with Roma tomato treatment water, log reductions in the tank water were significantly greater $(P<0.05)$ with higher airflow rates and higher chlorine concentrations. Chlorine as a liquid sanitizer (200 ppm) was found to reduce the population of L. monocytogenes by 1.5-2 log in fresh cut produce (Zhang and Farber, 1996). Similar results were reported for Salmonella inactivation, where chlorine treatment (100-200 $\mathrm{ppm}$ ) of fresh produce resulted in 1-2 log reduction of Salmonella populations (Wei et al., 1995; Zhuang et al., 1995; Weissinger et al., 2000). In this study, $S$. Newport was reduced by $>2$ logs when 150 ppm NaOCL was in the tank water with no bubbles.

Other researchers have reported that chlorine treatments are more effective against microorganisms when coupled with cavitation induced by ultrasonication of a liquid. For example, Seymour et al. (2002) used both chlorine and cavitation to remove an average of $2.7 \mathrm{log}$ of Salmonella Typhimurium from lettuce leaves. They observed only a $1.5 \mathrm{log}$ reduction from cavitation treatment alone and a $1.7 \mathrm{log}$ reduction from using chlorine alone.) Similar results were achieved in removing E. coli on fresh lettuce, where pathogen populations were reduced by 2 logs (Piyasena et al., 2003). Chlorine wash and cavitation treatment were both used in removing $E$. coli on organic spinach leaves, which increased efficacy by $1.1 \log$ reduction of $E$. coli, more than chlorine alone (Zhou et al., 2009).

In this research, combining both cavitating bubbles and chlorine in the tank water resulted in greater efficacy of removing or inactivating $S$. Newport from the surface of Roma tomatoes and cantaloupe than with cavitation or chlorine alone (Figures 7, 8). This is consistent with research performed with other pathogens and raw fruits or vegetables (Wei et al., 1995; Zhuang et al., 1995; Weissinger et al., 2000; Singh et al., 2002).

\section{CONCLUSIONS}

Inertial cavitation treatments (14 SLPM) reduced the population of Listeria monocytogenes and Salmonella Newport on the surface of fresh Roma tomatoes and cantaloupes by $0.6-1.3$ log greater than that measured when no bubbles were applied. Enumeration of the remaining treatment water post-cavitation, also showed a $0.5-1.0 \mathrm{log}$ decrease in bacterial concentrations as airflow increased, proposing that cavitation has an effect on organisms remaining in the water, as well as on the surface on fruits. Additional efficacy was observed when cavitation was combined with chlorine in the treatment tank. Cavitation treatments were found to be similarly effective as chlorine, under 
our test conditions, for removing or inactivating pathogens from the surface of fresh Roma tomatoes and cantaloupes. However, chlorine was more effective at reducing pathogenic populations in the water in the treatment tank. This is consistent with the use of chlorine in the food industry as a method to reduce pathogenic populations in wash waters (Wei et al., 1985).

Food safety can be enhanced by physical processes, including injected bubbles, to remove and inactivate common foodborne pathogens on the surface of fresh produce. This technology holds great promise in potentially providing widespread utility among a variety of food surfaces and applications in other antimicrobial treatments in the food industry, at low costs, low treatment times, and energetically sustainable manners. Cavitating bubbles can be generated in various numbers, diameters and velocities and can be applied at different distances, vectors, and concentrations against a food or food contact surface. These bubbles can be effective for removing bacteria from these surfaces. Further research with inertial cavitation should be conducted with other microbial pathogens and with other food types, including those with an intricate topography that may be better sanitized with injected cavitation bubbles.

\section{REFERENCES}

Asplund, K., and Nurmi, E. (1991). The growth of Salmonella in tomatoes. Int. J. Food Microbiol. 13, 177-181. doi: 10.1016/0168-1605(91)90059-X

Bastos, M. D. S. R., Soares, N. D. F. F., de Andrade, N. J., Arruda, A. C., and Alves, R. E. (2005). The effect of the association of sanitizers and surfactant in the microbiota of the Cantaloupe (Cucumis melo L.) melon surface. Food Control 16, 369-373. doi: 10.1016/j.foodcont.2004.04.002

Bennett, S. D., Littrell, K. W., Hill, T. A., Mahovic, M., and Behravesh, C. B. (2015). Multistate foodborne disease outbreaks associated with raw tomatoes, United States, 1990-2010: a recurring public health problem. Epidemiol. Infect. 143, 1352-1359. doi: 10.1017/S0950268814002167

Beuchat, L. R. (2002). Ecological factors influencing survival and growth of human pathogens on raw fruits and vegetables. Microbes Infect. 4, 413-423. doi: 10.1016/S1286-4579(02)01555-1

Birkhoff, G. (1957). Jets, wakes and cavities. J. Fluid Mech. 3, 437-440.

Boriss, H. (2014). Melon Profile. Agricultural Marketing Service. Available online at: http://www.agmrc.org/commodities-products/vegetables/melon-profile/ (Accessed August 8, 2016).

Burnett, S. L., and Beuchat, L. R. (2000). Human pathogens associated with raw produce and unpasteurized juices, and difficulties in decontamination. J. Ind. Microbiol. Biotechnol. 25, 281-287. doi: 10.1038/sj.jim.7000106

Center for Disease Control and Prevention (2012). Multistate Outbreak of Listeriosis Linked to Whole Cantaloupes From Jensen Farms, Colorado (Final Update). Available online at: http://www.cdc.gov/listeria/outbreaks/ cantaloupes-jensen-farms/. (Accessed August 8, 2016).

Center for Diseases Control and Prevention (2010). Salmonella- Technical. Available online at: https://www.cdc.gov/salmonella/general/technical.html (Accessed December 19, 2015).

Chahine, G. L., Kapahi, A., Choi, J. K., and Hsiao, C. T. (2016). Modeling of surface cleaning by cavitation bubble dynamics and collapse. Ultrason. Sonochem. 29, 528-549. doi: 10.1016/j.ultsonch.2015.04.026

Chandrapala, J., Oliver, C., Kentish, S., and Ashokkumar, M. (2012). Ultrasonics in food processing-food quality assurance and food safety. Trends Food Sci. Technol. 26, 88-98. doi: 10.1016/j.tifs.2012.01.010

Eikmeier, D. (2016). Salmonella Newport Outbreak Associated With Tomatoes Consumed at Burrito Chain a: Lessons Learned for Investigating Chain a

\section{DATA AVAILABILITY}

The raw data supporting the conclusions of this manuscript will be made available by the corresponding author, without undue reservation, to any qualified researcher.

\section{AUTHOR CONTRIBUTIONS}

JL, JE, and SJ conceived and designed the experiments. JL performed the experiments. JL and JE performed statistical analysis. All authors wrote sections of the manuscript and contributed revisions to the manuscript.

\section{FUNDING}

Research was supported in part by the College of Agriculture and Life Sciences and the Institute for Critical Technology and Applied Science of Virginia Tech.

\section{ACKNOWLEDGMENTS}

The authors acknowledge the editorial assistance of Noah Wax, Department of Biological Sciences, Virginia Tech.

Outbreaks. Council of State and Territorial Epidemiologists. Available online at: https://cste.confex.com/cste/2016/webprogram/Paper6618.html (Accessed August 8, 2016).

Feng, H. (2011). "The thermodynamic and kinetic aspects of power ultrasound processes," in Ultrasound Technologies for Food and Bioprocessing, eds H. Feng, G. V. Barbosa, and J. Weiss (New York, NY: Springer), 107-123. doi: 10.1007/978-1-4419-7472-3_4

Food and Drug Administration (2003). Quantitative Assessment of Relative Risk to Public Health From Foodborne Listeria monocytogenes Among Selected Categories of Ready to Eat Foods. Available online at: http://www.fda.gov/ downloads/Food/FoodScienceResearch/UCM197330.pdf (Accessed December 17, 2015).

Food and Drug Administration (2015). Bad Bug Book: Foodborne Pathogenic Microorganisms and Natural Toxins Handbook. Available online at: http://www. fda.gov/Food/FoodborneIllnessContaminants/CausesOfIllnessBadBugBook/ default.htm (Accessed March 9, 2016).

Food and Drug Administration (2016) Detection and Enumeration of Listeria monocytogenes. Bacteriological Analytical Manual, Ch. 10. Available online at: http://www.fda.gov/Food/FoodScienceResearch/LaboratoryMethods/ ucm071400.htm (Accessed February 2, 2016).

Greene, S. K., Daly, E. R., Talbot, E. A., Demma, L. J., Holzbauer, S., Patel, N. J., et al. (2008). Recurrent multistate outbreak of Salmonella Newport associated with tomatoes from contaminated fields, 2005. Epidemiol. Infect. 136, 157-165. doi: 10.1017/S095026880700859X

Lopez, K., Phalen, K., Vahl, C. I., Roberts, K. R., and Getty, K. J. (2016). Investigation of handling practices for fresh produce and the efficacy of commercially available produce washes on removal of pathogens and natural microflora on whole cantaloupe surfaces. Food Control 68, 251-259. doi: 10.1016/j.foodcont.2016. 03.050

Marotti, J., Heger, S., Tinschert, J., Tortamano, P., Chuembou, F., Radermacher, K., et al. (2013). Recent advances of ultrasound imaging in dentistry-a review of the literature. Oral Surg. Oral Med. Oral Pathol. Oral Radiol. 115, 819-832. doi: 10.1016/j.oooo.2013.03.012

McClements, D. J. (1995). Advances in the application of ultrasound in food analysis and processing. Trends Food Sci. Technol. 6, 293-299. doi: 10.1016/S0924-2244(00)89139-6 
O’Donnell, C. P., Tiwari, B. K., Bourke, P., and Cullen, P. J. (2010). Effect of ultrasonic processing on food enzymes of industrial importance. Trends Food Sci. Technol. 21, 358-367. doi: 10.1016/j.tifs.2010.04.007

Piyasena, P., Mohareb, E., and McKellar, R. C. (2003). Inactivation of microbes using ultrasound: a review. Int. J. Food Microbiol. 87, 207-216. doi: 10.1016/S.0168-1605(03)00075-8

R Core Team (2016). R: A Language and Environment for Statistical Computing. Vienna: R Foundation for Statistical Computing . Available online at: http:// www.R-project.org/ (Accessed October 10, 2016).

Rayleigh, L. (1917), On the pressure developed in a liquid during the collapse of a spherical Cavity. Philos. Mag. 34, 94-98. doi: 10.1080/14786440808635681

Ritenour, M., Sargent, S. A., and Bartz, J. A. (2002). Chlorine Use in Produce Packing Lines. Gainesville, FL: University of Florida Cooperative Extension Service, Institute of Food and Agricultural Sciences, EDIS.

Scallan, E., Hoekstra, R. M., Angulo, F. J., Tauxe, R. V., Widdowson, M. A., and Roy, S. L. (2011). Foodborne illness acquired in the United States-major pathogens. Emerg. Infect. Dis. 17, 7-15. doi: 10.3201/eid1701.P11101

Scouten, A. J., and Beuchat, L. R. (2002). Combined effects of chemical, heat and ultrasound treatments to kill Salmonella and Escherichia coli O157:H7 on alfalfa seeds. J. Appl. Microbiol. 92, 668-674. doi: 10.1046/j.1365-2672.2002.01571.x

Seymour, I. J., Burfoot, D., Smith, R. L., Cox, L. A., and Lockwood, A. (2002), Ultrasound decontamination of minimally processed fruits and vegetables. Int. J. Food Sci. Technol. 37, 547-557. doi: 10.1046/j.1365-2621.2002.00613.x

Singh, N., Singh, R. K., Bhunia, A. K., and Stroshine, R. L. (2002). Efficacy of chlorine dioxide, ozone, and thyme essential oil or a sequential washing in killing Escherichia coli O157: H7 on lettuce and baby carrots. LWT Food Sci. Technol. 35, 720-729. doi: 10.1006/fstl.2002.0933

Ukuku, D. O., and Fett, W. (2002). Behavior of Listeria monocytogenes inoculated on cantaloupe surfaces and efficacy of washing treatments to reduce transfer from rind to fresh-cut pieces. J. Food Prot. 65, 924-930. doi: 10.4315/0362-028X-65.6.924

USDA, Economic Research Service (ERS) (2010). ERS - Vegetables \& Pulses: Tomatoes. Available online at: http://www.ers.usda.gov/topics/crops/ vegetables-pulses/tomatoes.aspx (Accessed December 19, 2015).

van Wijngaarden, L. (2016). Mechanics of collapsing cavitation bubbles. Ultrason. Sonochem. 29, 524-527. doi: 10.1016/j.ultsonch.2015.04.006

Wang, H., Feng, H., Liang, W., Luo, Y., and Malyarchuk, V. (2009). Effect of surface roughness on retention and removal of Escherichia coli O157:H7 on surfaces of selected fruits. J. Food Sci. 74, E8-E15. doi: 10.1111/j.1750-3841.2008.00998.x
Wang, H., and Ryser, E. T. (2014). Salmonella transfer during pilot plant scale washing and roller conveying of tomatoes. J. Food Prot. 77, 380-387. doi: 10.4315/0362-028X.JFP-13-314

Waters, B. W., and Hung, Y. C. (2014). The effect of organic loads on stability of various chlorine-based sanitizers. Int. J. Food Sci. Technol. 49, 867-875. doi: 10.1111/ijfs.12379

Wei, C. I., Cook, D. L., and Kirk, J. R. (1985). Use of chlorine compounds in the food industry. Food Technol. 39, 107-115.

Wei, C. I., Huang, T. S., Kim, J. M., Lin, W. F., Tamplin, M. L., and Bartz, J. A. (1995). Growth and survival of Salmonella Montevideo on tomatoes and disinfection with chlorinated water. J. Food Prot. 58, 829-836. doi: 10.4315/0362-028X-58.8.829

Weissinger, W. R., Chantarapanont, W., and Beuchat, L. R. (2000). Survival and growth of Salmonella Baildon in shredded lettuce and diced tomatoes, and effectiveness of chlorinated water as a sanitizer. Int. J. Food Microbiol. 62, 123-131. doi: 10.1016/S0168-1605(00) 00415-3

Zhang, S., and Farber, J. M. (1996). The effects of various disinfectants against Listeria monocytogenes on fresh-cut vegetables. Food Microbiol. 13, 311-321. doi: 10.1006/fmic.1996.0037

Zhou, B., Feng, H., and Luo, Y. (2009). Ultrasound enhanced sanitizer efficacy in reduction of Escherichia coli O157: H7 population on spinach leaves. J. Food Sci. 74, M308-M313. doi: 10.1111/j.1750-3841.2009. 01247.x

Zhuang, R. Y., Beuchat, L. R., and Angulo, F. J. (1995). Fate of Salmonella Montevideo on and in raw tomatoes as affected by temperature and treatment with chlorine. Appl. Environ. Microbiol. 61, 2127-2213

Conflict of Interest Statement: The authors declare that the research was conducted in the absence of any commercial or financial relationships that could be construed as a potential conflict of interest.

Copyright (c) 2018 Lee, Eifert, Jung and Strawn. This is an open-access article distributed under the terms of the Creative Commons Attribution License (CC BY). The use, distribution or reproduction in other forums is permitted, provided the original author(s) and the copyright owner(s) are credited and that the original publication in this journal is cited, in accordance with accepted academic practice. No use, distribution or reproduction is permitted which does not comply with these terms. 